\title{
Desempenho e desenvolvimento do trato digestório superior de bezerros leiteiros alimentados com concentrado de diferentes formas físicas ${ }^{1}$
}

\author{
Carla Maris Machado Bittar², Lucas Silveira Ferreira ${ }^{3}$, Flávio Augusto Portela Santos², \\ Maity Zopollatto ${ }^{3}$
}

\author{
${ }^{1}$ Projeto parcialmente financiado pela NUTRON Alimentos Ltda. \\ 2 Departamento de Zootecnia, USP/ESALQ, Piracicaba/SP. \\ 3 Pós-Graduação em Ciência Animal e Pastagens, Departamento de Zootecnia, USP/ESALQ, Piracicaba/SP.
}

\begin{abstract}
RESUMO - Objetivou-se com este trabalho avaliar o efeito da forma física do concentrado no desempenho e no desenvolvimento ruminal de bezerros leiteiros. Foram utilizados 22 bezerros Holandeses com peso corporal inicial médio de 43,2 kg, alojados individualmente e alimentados com dieta líquida (4 L/d) e concentrado inicial de duas formas físicas (peletizada ou farelada). O consumo de concentrado inicial foi monitorado diariamente e os animais pesados semanalmente, sempre após o fornecimento da dieta líquida, pela manhã. Após dez semanas, quatro bezerros de cada tratamento foram abatidos para coleta de amostras de fluido ruminal para determinação do pH e das concentrações de ácidos graxos de cadeia curta (AGCC) e de $\mathrm{N}-\mathrm{NH}_{3}$ ruminal. Também foram realizadas medidas morfométricas do trato digestório superior. Não houve efeito da forma física no consumo de concentrado inicial, no peso corporal ou no ganho de peso diário dos animais. A forma física do concentrado inicial também não afetou o pH, as concentrações de AGCC ou de $\mathrm{N}_{-} \mathrm{NH}_{3}$ ruminal, assim como as medidas morfométricas do trato digestório superior, à exceção da capacidade do rúmen e do peso do abomaso, que foram maiores nos animais alimentados com concentrado peletizado. O fornecimento de concentrado farelado pode ser uma alternativa para a redução de custo de produção, uma vez que a forma física do concentrado não afeta o desempenho ou o desenvolvimento do trato digestório superior de bezerros leiteiros.
\end{abstract}

Palavras-chave: abomaso, farelado, omaso, peletizado, retículo-rúmen, trato digestório

\section{Performance and ruminal development of dairy calves fed starter concentrate with different physical forms}

\begin{abstract}
The physical form of concentrate on the performance and rumen development on dairy calves was evaluated in this experiment. Twenty-two Holstein male calves, with $42.3 \mathrm{~kg}$ initial body weight, were individually housed, fed $4 \mathrm{~L} / \mathrm{d}$ of liquid diet and starter concentrate in two physical forms (pelleted or coarsely ground). Starter concentrate intake was monitored daily and calves were weighted weekly, always after the morning liquid diet feeding. After 10 weeks, four calves from each treatment were slaughtered and rumen samples were taken for $\mathrm{pH}$, rumen short chain fatty acids (SCFA) and $\mathrm{N}-\mathrm{NH}_{3}$ concentration. Morphometric measurement of the forestomach was also evaluated. There was no effect of the physical form on starter concentrate intake, body weight, and daily gain. The physical form of the concentrate also had no effects on $\mathrm{pH}$, SCFA or $\mathrm{N}-\mathrm{NH}_{3}$ rumen concentration, nor on the morphometric measurements of the forestomach, except for rumen capacity and abomasum weight, which were higher for animals fed pelleted starter concentrate. Coarsely ground starter concentrate may be an alternative to reduced production costs since the physical form of the concentrate had no effect on performance or in the development of forestomach of dairy calves.
\end{abstract}

Key Words: abomasum, coarsely ground concentrate, digestive tract, omasum, pelleted concentrate, reticulum-rumen

\section{Introdução}

O desaleitamento precoce é uma importante alternativa de manejo na criação de fêmeas de reposição, pois o custo de alimentação desses animais é reduzido com a retirada do leite e a introdução de misturas concentradas como dieta principal. Além disso, o menor tempo para o aleitamento desses animais reduz o custo com mão-de-obra.

O desenvolvimento de bezerros recém-nascidos à condição de ruminante funcional envolve uma série de mudanças anatômicas e fisiológicas do aparelho digestivo (Beharka et al., 1998). Para que a taxa de crescimento dos 
animais não seja afetada após o desaleitamento, o rúmen deve estar parcialmente desenvolvido e ser capaz de absorver e metabolizar os produtos finais da fermentação.

A aceleração do desenvolvimento do rúmen está associada ao consumo de alimentos sólidos e à produção de ácidos graxos de cadeia curta (AGCC), especialmente os ácidos butírico e propiônico (Baldwin et al., 2004). A forma física do concentrado inicial pode afetar o consumo, por isso, é de interesse econômico o fornecimento de concentrados sob formas físicas que estimulem o consumo precoce.

Segundo Coverdale et al. (2004), o tamanho de partícula da ração também pode afetar o ambiente ruminal, a produção de AGCC e a estrutura e função das papilas ruminais. Rações finamente moídas reduzem o $\mathrm{pH}$ ruminal, principalmente por reduzirem a ruminação e o fluxo de saliva (Santini et al., 1983), diminuindo a população de bactérias celulolíticas (Beharha et al., 1998). Assim, Warner et al.(1973) sugerem que pelo menos $50 \%$ das partículas que compõem o concentrado inicial sejam maiores que $1,19 \mathrm{~mm}$.

Os maiores efeitos do tamanho de partícula no desempenho animal são observados no consumo de concentrado, no ganho de peso e no desenvolvimento ruminal. Em alguns trabalhos recentes, pesquisadores avaliaram o efeito da forma física do concentrado inicial e não observaram diferenças no consumo ou no ganho de peso ao compararem concentrados peletizados com farelados para bezerros em aleitamento (Franklin et al., 2003; Veloso et al., 2006; Ziegler et al., 2006). Por outro lado, Warner (1991) verificou que bezerros alimentados com ração de forma física grosseira apresentaram maior ganho de peso e maior eficiência alimentar em comparação a bezerros alimentados com a ração na forma farelada.

Entretanto, poucos trabalhos têm sido realizados com o objetivo de avaliar a relação entre a forma física do concentrado e o desenvolvimento ruminal em animais em sistema de desaleitamento precoce. Neste trabalho, objetivou-se avaliar o efeito da forma física de concentrados (peletizado ou farelado) no desempenho e no desenvolvimento do trato digestório superior de bezerros de rebanhos leiteiros aleitados com sucedâneo lácteo até a sétima semana de vida.

\section{Material e Métodos}

Foram utilizados 22 bezerros machos da raça Holandesa, provenientes de rebanho comercial, com peso inicial médio de 43,2 kg, em delineamento de blocos casualizados. Após o nascimento, os animais foram separados das mães e receberam 2 a 3 litros de colostro a cada 12 horas até o segundo dia de vida, quando foram transportados para o
Centro de Pesquisa em Nutrição Animal (CPNA) da Nutron Alimentos Ltda (Mogi Mirim, São Paulo), onde o experimento foi conduzido durante oito semanas.

Os animais foram distribuídos nos blocos, de acordo com a data de nascimento e o peso ao nascer. Os tratamentos consistiram do fornecimento de concentrado inicial sob duas formas físicas: peletizado ou farelado (Tabela 1). Metade do concentrado foi misturada na forma farelada e a outra foi submetida ao processo de peletização.

Para determinação do tamanho médio de partícula do concentrado farelado (Figura 1), utilizou-se o método descrito por Yu et al. (1998). O tamanho médio das partículas do concentrado foi de $0,97 \mathrm{~mm}$ e o diâmetro e comprimento médio dos peletes, medidos com paquímetro, foram de $5 \mathrm{~mm}$ e $1,65 \mathrm{~mm}$, respectivamente.

Tabela 1 - Composição do concentrado inicial

\begin{tabular}{|c|c|c|}
\hline Ingrediente & \multicolumn{2}{|c|}{ Concentrado inicial, \%MS } \\
\hline Milho moído & \multicolumn{2}{|c|}{46,1} \\
\hline Farelo de soja & \multicolumn{2}{|c|}{25,9} \\
\hline Farelo de trigo & \multicolumn{2}{|c|}{18,0} \\
\hline Leite em pó & \multicolumn{2}{|c|}{6,0} \\
\hline$\underline{\text { Minerais e vitaminas }}$ & \multicolumn{2}{|c|}{4,0} \\
\hline \multirow[t]{2}{*}{ Composição química } & Peletizado & Farelado \\
\hline & \multicolumn{2}{|c|}{$\% \mathrm{MS}$} \\
\hline Proteína bruta & 20,63 & 20,80 \\
\hline Extrato etéreo & 3,45 & 3,58 \\
\hline Fibra bruta & 4,26 & 3,89 \\
\hline Cinzas & 6,32 & 6,78 \\
\hline Cálcio & 1,21 & 1,23 \\
\hline Fósforo & 0,64 & 0,68 \\
\hline \multicolumn{3}{|l|}{ Parâmetros de forma física } \\
\hline Tamanho médio de partícula, mm & - & 0,97 \\
\hline Diâmetro, mm & 5 & - \\
\hline Comprimento, mm & 1,65 & - \\
\hline
\end{tabular}

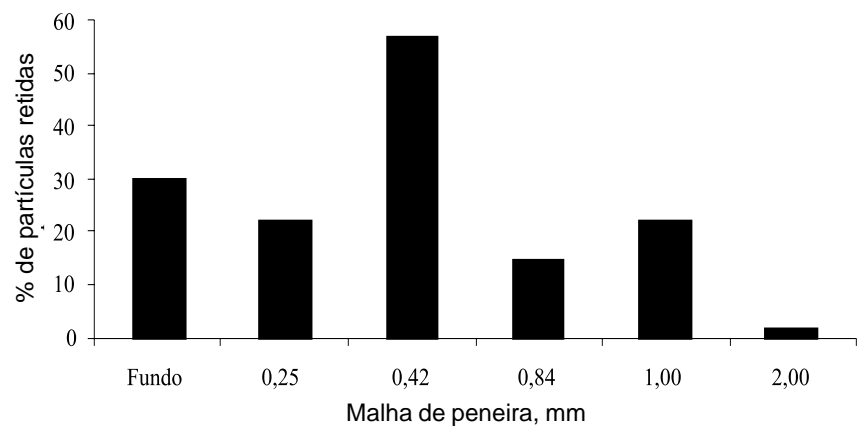

Figura 1 - Distribuição do tamanho de partícula do concentrado farelado. 
Os animais foram mantidos em gaiolas individuais e passaram a receber $4 \mathrm{~L}$ de leite pasteurizado até o 15ํㅓia de vida e sucedâneo de leite $\left(\right.$ Lactal $\left.^{\circledR}\right)$, do 16 o dia até o término do experimento, divididos em duas refeições (às 8 e 16 h).

Os animais tiveram livre acesso a água e receberam concentrado à vontade até consumo máximo de $2 \mathrm{~kg}$. $\mathrm{O}$ concentrado inicial foi fornecido diariamente, após a retirada das sobras do dia anterior. Os animais foram pesados semanalmente, em balança mecânica, sempre após o fornecimento da dieta líquida, no período da manhã.

O desaleitamento foi realizado de forma abrupta na sétima semana de vida. Quatro animais de cada tratamento foram abatidos por meio de atordoamento e sangria, com o corte da jugular, após colheita de sangue para determinação de glicose por leitura direta (Biochemistry Analizer YSI 2700, Yellow Spring, OH). A cavidade abdominal dos animais foi aberta e o retículo, rúmen, omaso e abomaso foram retirados, após a separação do tecido adiposo omental.

Uma amostra de fluido ruminal de aproximadamente $50 \mathrm{~mL}$ foi colhida de todas as porções do rúmen para imediata determinação do $\mathrm{pH}$, em potenciômetro digital (Digimed TE-902), e armazenada a $-10^{\circ} \mathrm{C}$ para posterior análise de ácidos graxos de cadeia curta (AGCC) e de $\mathrm{N}$-amoniacal ( $\left.\mathrm{N}-\mathrm{NH}_{3}\right)$. A determinação das concentrações de AGCC foi realizada conforme descrito por Campos et al. (2004) em cromatógrafo líquido-gasoso (Hewlett Packard 5890 Series II GC), equipado com integrador (Hewlett Packard 3396 Series II Integrator) e injetor automático (Hewlett Packard 6890 Series Injector). O padrão interno utilizado foi o ácido 2-metilbutírico, acrescentando, em cada tubo para leitura em cromatógrafo, $100 \mathrm{~mL}$ do padrão interno, $800 \mathrm{~mL}$ da amostra e $200 \mathrm{~mL}$ de ácido fórmico. Uma mistura de ácidos graxos de cadeia curta com concentração conhecida foi utilizada como padrão externo para calibração do integrador. As concentrações de $\mathrm{N}$-amoniacal foram determinadas conforme método de Chaney \& Marbach(1962), adaptado para leitura em placas de microtítulo em aparelho Microplate Reader BIO RAD, utilizando-se filtro para absorbância de $550 \mathrm{~nm}$.
Após a colheita da amostra de fluido ruminal, o conteúdo do trato digestório superior foi retirado por meio de lavagens com água, e os compartimentos divididos em retículo-rúmen, omaso e abomaso. Para determinação da capacidade máxima do retículo-rúmen, a saída desse compartimento foi fechada por meio de amarração; todo o retítulo-rúmen foi cheio com água até sua máxima capacidade e o volume medido em proveta. Depois da retirada do excesso de água dos tecidos, foram tomadas medidas de peso do retículo-rúmen, do omaso, do abomaso e dos quatro compartimentos em conjunto.

Amostras do epitélio do saco ventral do rúmen foram colhidas, preservadas em solução de formaldeído $10 \%$ e posteriormente avaliadas por meio de microscópio estereoscópico provido de escala. Como medidas de desenvolvimento ruminal, foram mensurados o número de papilas por $\mathrm{cm}^{2}$, a altura e a largura média das papilas. Conforme sugerido por Lesmeister et al. (2004), foram avaliadas três amostras por animal e mensuradas pelo menos dez papilas de cada amostra para determinação de altura e largura média.

Os dados de consumo de concentrado inicial, de peso corporal e ganho de peso foram analisados como medidas repetidas no tempo, pelo PROC MIXED; enquanto as medidas morfométricas do aparelho digestório superior foram analisadas pelo PROC GLM do programa estatístico SAS (1991).

\section{Resultados e Discussão}

Não houve efeito $(\mathrm{P}>0,05)$ da forma física do concentrado no peso corporal, no ganho de peso diário e no consumo médio de concentrado durante o período experimental (Tabela 2). Entretanto, como previsto, houve efeito da idade do animal $(\mathrm{P}<0,0001)$ sobre essas variáveis (Figura 2), com valores crescentes durante o período avaliado. Todavia, embora o efeito da idade tenha sido observado, a interação idade $\times$ forma física do concentrado não foi significativa.

Tabela 2 - Desempenho de bezerros de rebanhos leiteiros recebendo concentrado inicial peletizado ou farelado

\begin{tabular}{|c|c|c|c|c|c|c|}
\hline & \multicolumn{2}{|c|}{ Forma física do concentrado } & $\mathrm{EPM}^{1}$ & \multicolumn{3}{|c|}{$\mathrm{P}<$} \\
\hline Peso ao nascimento, kg & 42,87 & 43,62 & 0,55 & 0,406 & - & - \\
\hline Ganho de peso, g/dia & 413,5 & 406,0 & 37,62 & 0,880 & 0,0001 & 0,557 \\
\hline Consumo médio de concentrado, g/dia & 561,14 & 533,87 & 75,19 & 0,802 & 0,0001 & 0,882 \\
\hline
\end{tabular}

${ }^{1}$ EPM = erro-padrão da média.

${ }^{2} \mathrm{~T}$ = efeito de tratamento; $\mathrm{I}$ = efeito de idade (semana); TxI = interação forma física do concentrado $\times$ idade. 

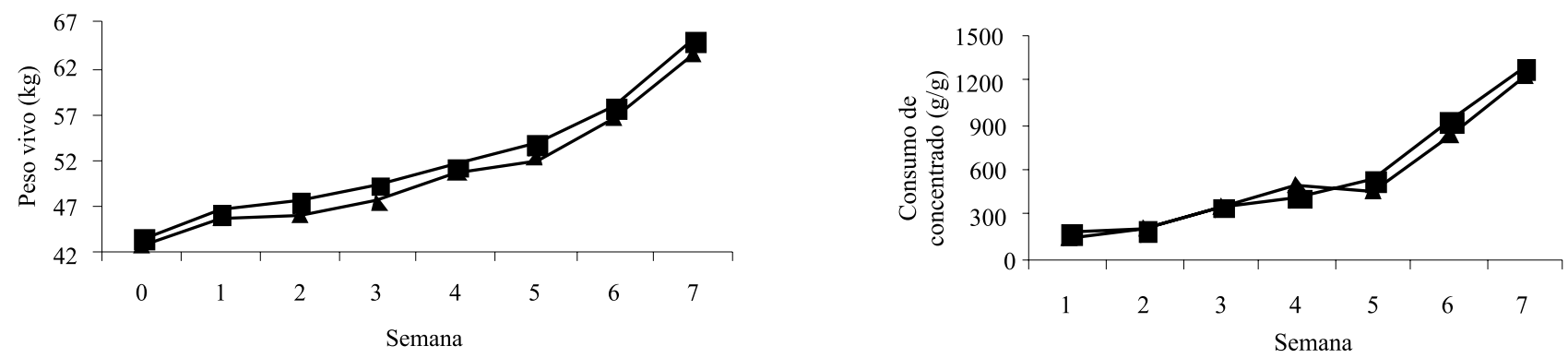

Figura 2 - Evolução temporal do peso vivo (kg) e do consumo de concentrado (g/dia) em bezerros alimentados com concentrado de diferentes formas físicas: farelado $(\boldsymbol{\square})$ ou peletizado $(\boldsymbol{\Delta})$.

Em virtude de sua relação com o desenvolvimento do rúmen, o consumo de alimento sólido, mais especificamente de concentrado, é utilizado como critério para o desaleitamento de bezerros. A recomendação tradicional, de Quigley III (1996b), é o desaleitamento de bezerros da raça Holandesa quando apresentam consumo de concentrado de aproximadamente $700 \mathrm{~g} /$ dia, durante três dias consecutivos. Uma vez que o consumo de alimento determina o peso vivo dos animais, Greenwood et al. (1997) demonstraram que bezerros podem ser desaleitados de forma adequada quando apresentam consumo equivalente a $1,5 \%$ do seu peso ao nascer. Neste experimento, os animais de ambos os grupos apresentaram consumo de concentrado adequado para o desaleitamento já a partir da sexta semana de vida.

As taxas de crescimento animal estão dentro do recomendado na literatura para animais em aleitamento (Heinrichs \& Losinger, 1998; Hoffman, 1997). Essas taxas de ganho ocorreram em resposta ao consumo de concentrado e garantiram ganhos diários satisfatórios. Os dados de desempenho animal corroboram os observados por outros autores (Franklin et al., 2003; Veloso et al., 2006) e indicam que animais alimentados com a mistura farelada, que normalmente tem menor custo, apresentaram o mesmo desempenho daqueles alimentados com concentrado peletizado. Embora Ghorbani et al. (2006) tenham observado tendência de maior consumo de concentrado inicial na forma peletizada, não houve diferença significativa no ganho de peso diário e no número de dias para o desaleitamento de bezerros entre as foram físicas de fornecimento do concentrado. Warner (1991) observou maior consumo e ganho de peso, além de menor idade à primeira ruminação (6 vs 3,7 semanas), em bezerros consumindo concentrado inicial farelado em comparação a animais consumindo concentrado na forma peletizada. Medina et al. (2002) observaram melhor desenvolvimento corporal em animais alimentados com concentrado peletizado em comparação ao concentrado farelado, entretanto, os concentrados tinham, além da forma física, composição nutricional diferente.

Conforme destacado por Franklin et al. (2003), misturas fareladas não devem ser finamente moídas e devem apresentar pelo menos 50\% das partículas com tamanho superior a 1,19 mm. Embora o tamanho médio de partícula tenha sido inferior ao recomendado por esses autores $(0,97 \mathrm{~mm}$, Tabela 1$)$, não houve redução no consumo de concentrado ou no desempenho dos animais. Assim, misturas fareladas podem ser adotadas com sucesso em programas de criação de bezerros leiteiros, pois não prejudicam o desempenho animal e podem reduzir os custos, desde que observados adequados tamanhos de partícula médios da mistura.

As concentrações plasmáticas de glicose não foram afetadas pela forma física do concentrado (Tabela 3). Esse parâmetro metabólico é de difícil resposta a alterações nutricionais, uma vez que está sob controle homeostático.

Tabela 3 - Glicose plasmática e parâmetros ruminais no momento do abate de bezerros leiteiros alimentados com concentrado inicial peletizado ou farelado

\begin{tabular}{|c|c|c|c|c|}
\hline & \multicolumn{2}{|c|}{$\begin{array}{l}\text { Forma física } \\
\text { do concentrado }\end{array}$} & \multirow[b]{2}{*}{$\mathrm{EPM}^{1}$} & \multirow[b]{2}{*}{$\mathrm{P}<$} \\
\hline & Peletizado & Farelado & & \\
\hline $\begin{array}{l}\text { Glicose plasmática, mg/dL } \\
\text { pH ruminal }\end{array}$ & $\begin{array}{c}72,90 \\
6,77\end{array}$ & $\begin{array}{c}69,22 \\
6,13\end{array}$ & $\begin{array}{l}2,93 \\
0,46\end{array}$ & $\begin{array}{l}0,410 \\
0,436\end{array}$ \\
\hline \multicolumn{5}{|c|}{ Ácidos graxos de cadeia curta, mMol } \\
\hline $\begin{array}{l}\text { Total }^{2} \\
\text { Ácido acético } \\
\text { Ácido propiônico } \\
\text { Ácido butírico } \\
\text { Ácido iso-butírico } \\
\text { Acético:butírico } \\
\mathrm{N}-\mathrm{NH}_{3} \text { ruminal, mg/dL }\end{array}$ & $\begin{array}{c}81,56 \\
34,06 \\
34,39 \\
7,13 \\
1,12 \\
1,08 \\
19,92\end{array}$ & $\begin{array}{c}122,17 \\
42,58 \\
63,84 \\
9,29 \\
0,57 \\
1,02 \\
16,95\end{array}$ & $\begin{array}{c}17,3 \\
4,45 \\
13,63 \\
1,70 \\
0,33 \\
0,38 \\
2,46\end{array}$ & $\begin{array}{l}0,148 \\
0,225 \\
0,177 \\
0,404 \\
0,282 \\
0,915 \\
0,426\end{array}$ \\
\hline
\end{tabular}

${ }^{1} \mathrm{EPM}$ = erro-padrão da média.

${ }^{2}$ Soma dos ácidos graxos de cadeia curta, incluindo os ácidos valérico e iso-valérico. 
No entanto, os valores observados, de 72,90 e 69,22 mg/dL, para animais alimentados com concentrado peletizado e farelado, respectivamente, são característicos de bezerros com o rúmen desenvolvido. Williams et al. (2001) e Nussio et al. (2003) observaram reduções na concentração de glicose plasmática com o avançar da idade dos animais, provavelmente em resposta à transição de pré-ruminante à ruminante funcional. Valores similares aos deste estudo foram observados por Quigley III \& Bernard (1992) para as concentrações de glicose ao desaleitamento.

Não houve efeito $(\mathrm{P}>0,05)$ da forma física do concentrado sobre o padrão de fermentação ruminal no momento do desaleitamento (Tabela 3). Beharka et al. (1998) também não observaram efeitos da forma física do concentrado nos parâmetros ruminais ao final do período experimental, embora tenham observado diferenças no $\mathrm{pH}$ na $4^{\mathrm{a}}$ e $6^{\underline{a}}$ semanas de vida e na concentração de $\mathrm{N}^{-\mathrm{NH}_{3}}$ na $2^{\underline{a}}$ e $6^{\underline{a}}$ semanas de vida dos animais, com maiores valores em animais alimentados com concentrado de textura mais grosseira. Greenwood et al. (1997) também não observaram efeito da forma física no $\mathrm{pH}$ ruminal de bezerros jovens.

Também não foram observados neste estudo efeitos significativos da forma física do concentrado nas concentrações molares de AGCC total $(\mathrm{P}<0,15)$ e ácido propiônico $(\mathrm{P}<0,18)$, apesar da grande diferença numérica. O processo de peletização requer que os ingredientes do concentrado sejam finamente moídos. Assim, quando esse alimento chega ao rúmen, sua estrutura física é alterada e transformada em partículas finas, que têm alta taxa de degradação. É possível que a tendência para menores concentrações de AGCC total e de ácido propiônico se deva à rápida fermentação de carboidratos logo após o fornecimento, à redução no $\mathrm{pH}$ ruminal, ao aumento na permeabilidade da parede ruminal e à conversão dos ácidos à sua forma dissociada, favorecendo a absorção destes ácidos pela parede ruminal (Bergman, 1990). No entanto, esses dados se referem somente ao momento do abate; não há dados relativos ao perfil de fermentação no tempo após o fornecimento de concentrado. Entretanto, como sugerido por Greenwood et al. (1997), partículas finamente moídas, com alta taxa de fermentação, normalmente resultam em queratinização e deformação de papilas, processo denominado paraqueratose, além de sedimentação de alimento entre papilas, o que implica menor capacidade de absorção de produtos da fermentação ruminal. As concentrações de AGCC total e de ácido propiônico são comparáveis àquelas reportadas por Greenwood et al. (1997), embora neste trabalho as concentrações molares de ácido acético tenham sido bem menores que as observadas por aqueles autores.
Tabela 4 - Medidas morfométricas do trato digestório superior de bezerros leiteiros recebendo concentrado inicial de diferentes formas físicas

\begin{tabular}{lccccc}
\hline & \multicolumn{3}{c}{$\begin{array}{c}\text { Forma física } \\
\text { do concentrado }\end{array}$} & & \\
\cline { 2 - 3 } & Peletizado & Farelado & & \\
& EPM $^{1}$ & $\mathrm{P}<$ \\
\hline Peso ao abate, kg & 72,6 & 69,8 & 1,34 & 0,231 \\
Trato superior total, g & $1.832,0$ & $1.982,0$ & 103,78 & 0,381 \\
Retículo-rúmen, g & $1.248,0$ & $1.295,0$ & 88,8 & 0,733 \\
Retículo-rúmen, \% trato total & 67,69 & 64,87 & 1,74 & 0,335 \\
Volume, L & $10,00 \mathrm{~b}$ & $11,97 \mathrm{a}$ & 0,37 & 0,033 \\
Omaso, g & 256,5 & 279,5 & 38,8 & 0,703 \\
Omaso, \% trato total & 14,27 & 14,10 & 1,52 & 0,942 \\
Abomaso, g & $327,5 \mathrm{~b}$ & $407,5 \mathrm{a}$ & 16,7 & 0,043 \\
Abomaso, \% trato total & 18,04 & 21,02 & 2,31 & 0,428 \\
Papilas ruminais, número/cm & 108,00 & 143,00 & 23,48 & 0,405 \\
$\quad$ Altura, mm & 3,367 & 2,432 & 0,396 & 0,194 \\
Largura, mm & 1,351 & 1,075 & 0,153 & 0,333 \\
\hline
\end{tabular}

${ }^{1} \mathrm{EPM}=$ erro-padrão da média.

Os pesos dos compartimentos, assim como os pesos em porcentagem do trato digestório total não foram afetados pela forma física do concentrado $(\mathrm{P}>0,05)$, exceto para o peso do abomaso $(\mathrm{P}<0,05)$ (Tabela 4). Maior peso de abomaso pode sugerir menor desenvolvimento ruminal. Entretanto, a proporção desse órgão em relação ao trato digestório total comprova sua menor importância como órgão de digestão nestes animais. Foram observados efeitos significativos para o volume máximo do retículo-rúmen $(\mathrm{P}<0,05)$. Entretanto, essa é uma medida mais relacionada à capacidade de consumo que à maturidade fisiológica do compartimento. Beharka et al. (1998) observaram resultados semelhantes em bezerros alimentados com rações fareladas de textura fina ou mais grosseira. Greenwood et al. (1997) também não observaram diferenças no peso do retículo-rúmen de bezerros alimentados com concentrados de diferentes formas físicas e índices de abrasividade. No entanto, verificaram diferenças no epitélio do rúmen com menores índices de queratinização para o fornecimento do concentrado com maior abrasividade.

Suárez et al. (2006) observaram maior peso do rúmen de bezerros consumindo dietas com a mesma forma física (farelada), mas com maior proporção de FDN ou pectina quando comparados a animais consumindo dietas ricas em amido. A maior proporção de FDN no concentrado de bezerros aumenta o peso do rúmen, em decorrência do seu efeito como estimulador do desenvolvimento da musculatura desse órgão. Entretanto, no trabalho de Suárez et al (2006), ao contrário do que normalmente se espera, o epitélio ruminal não sofreu estímulo ao desenvolvimento, e não foram observadas diferenças no desenvolvimento de 
papilas. Neste trabalho, a forma física do concentrado de mesma composição em FDN não afetou o peso do retículorúmen, o que sugere que o concentrado na forma de pélete não estimula o desenvolvimento da musculatura ruminal $(\mathrm{P}>0,05)$.

O desenvolvimento do epitélio ruminal avaliado com medidas de altura e largura de papilas também não foi afetado pela forma física do concentrado inicial $(\mathrm{P}>0,05)$. Da mesma forma, o número de papilas por $\mathrm{cm}^{2}$ também não apresentou diferenças significativas $(\mathrm{P}>0,05)$. Beharka et al. (1998) observaram valores similares para altura de papilas de bezerros com 10 semanas de idade alimentados com ração com diferentes formas físicas. Grewnwood et al. (1997) constataram efeito direto do tamanho de partícula dos concentrados avaliados no comprimento e no índices ramificação de papilas ruminais de bezerros. O concentrado com menor tamanho médio de partícula resultou em papilas com maiores comprimentos, mas também com maior nível de ramificação.

Muitos trabalhos têm confirmado que o desenvolvimento de papilas, responsável pela absorção de produtos finais de fermentação, depende principalmente da presença de alimentos sólidos no rúmen e da produção de ácidos graxos de cadeia curta resultantes de fermentação (Tamate et al., 1962; Murdock \& Wallenius, 1980; Quigley III, 1996a). Desta forma, o adequado desenvolvimento de papilas é resultado da ação de produtos de fermentação ruminal, além do estímulo físico causado pelo alimento consumido. Entretanto, a peletização do concentrado inicial, isoladamente, parece não causar efeito físico suficiente no desenvolvimento da parede epitelial ruminal em comparação a concentrados iniciais com mesma composição química.

\section{Conclusões}

A forma física do concentrado inicial não afeta o consumo, o ganho de peso ou o desenvolvimento do trato digestório superior de bezerros leiteiros, assim, o fornecimento de concentrado farelado constitui alternativa para redução do custo de produção de bezerros leiteiros.

\section{Literatura Citada}

BALDWIN VI, R.L.; McLEOD, K.R.; KLOTZ, J.L. et al. Rumen development, intestinal growth and hepatic metabolism in the pre- and postweaning ruminant. Journal of Dairy Science, v.87, p.E55-E65, 2004.

BEHARKA, A.A.; NAGARAJA, T.G.; MORRILL, G.A. et al. Effects of form of the diet on anatomical, microbial, and fermentative development of the rumen of neonatal calves. Journal of Dairy Science, v.81, n.7, p.1946-1955, 1998.
BERGMAN, E.N. Energy contributions of volatile fatty acids from the gastrointestinal tract in various species. Physiological Reviews, v.70, p.567-590, 1990.

CAMPOS, F.P.; NUSSIO, C.M.B.; NUSSIO, L.G. Métodos de análise de alimentos. Piracicaba: Fundação de Estudos Agrários Luiz de Queiroz, 2004. 135p.

CHANEY A.L.; MARBACH, E.P. Modified reagents for determination of urea and ammonia. Clinical Chemistry, v.8, p.130-132, 1962.

COVERDALE, J.A.; TYLER H.D; QUIGLEY III, J.D. et al. Effect of various levels of forage and form of diet on rumen development and growth in calves. Journal of Dairy Science, v.87, p.25542562, 2004.

FRANKLIN, S.T.; AMARAL-PHILIPS, D.M.; JACKSON, J.A. et al. Health and performance of Holstein calves that sucked or were hand-fed colostrums and were fed one of three physical starter. Journal of Dairy Science, v.86, p.2145-2153, 2003.

GREENWOOD, R.H.; MORRIL, J.L.; TITGEMEYER, E.E. et al. A new method of measuring diet abrasion and its effect on the development of the forestomach. Journal of Dairy Science, v.80, p.2534-2541, 1997.

GHORBANI, G.R.; VARZANEH, M.B.; NIKKHAH, A. Physical form of starter concentrate for young Holstein calves. Journal of Animal Science, v.84, p.363-363, 2006 (suppl. 1).

HEINRICHS, A.J.; LOSINGER, W.C. Growth of Holstein dairy heifers in the United States. Journal of Animal Science, v.76, p.1254-1260, 1998.

HOFFMAN, P. Optimum body size of Holstein replacement heifers Journal of Animal Science, v.75, p.836-845, 1997.

LESMEISTER, K.E.; TOZER, P.R.; HEINRICHS, A.J. Development and analysis of a rumen tissue sampling procedure. Journal of Dairy Science, v.87, n.5, p.1336-1344, 2004.

MEDINA, R.B.; LÜDER, W.R.; FISCHER, V. et al. Desaleitamento precoce de terneiros da raça holandês Preto e branco utilizando sucedâneo do leite ou leite e concentrado farelado ou peletizado. Revista Brasileira de Agrociência, v.8, n.1, p.61-65, 2002.

MURDOCK, F.R.; WALLENIUS, R.W. Fiber sources for complete calf starter rations. Journal of Dairy Science, v.63, p.1869, 1980.

NUSSIO, C.M.B.; RODRIGUES, A.A.; SANTOS, F.A.P. et al Avaliação de critérios para desaleitamento de bezerras leiteiras. In: REUNIÃO ANUAL DA SOCIEDADE BRASILEIRA DE ZOOTECNIA, 40., 2003, Santa Maria. Anais... Santa Maria: Sociedade Brasileira de Zootecnia, 2003. (CD-ROM).

QUIGLEY III, J.D.; BERNARD, J.K. Effects of nutrient source and time of feeding on changes in blood metabolites in young calves. Journal of Animal Science, v.70, p.1543-1549, 1992.

QUIGLEY III, J.D. Effects of lasalocid in milk replacer and calf starter on growth, intake, and fecal oocyst shedding in calves challenged with Eimeria. Journal of Dairy Science, v.79, p.154, 1996a (suppl.1).

QUIGLEY III, J.D. Feeding prior to weaning. In: CALVES, HEIFERS AND DAIRY PROFITABILITY NATIONAL CONFERENCE, 1996, Pennsylvania. Proceedings... Ithaca: Northeast Regional Agricultural Engineering Service Cooperative Extension, 1996b. p. 245-255.

SANTINI, F.J.; HARDIE, A.R.; JORGENSEN, N.A. et al. Proposed use of adjusted intake based on forage particle length for calculation of roughage indexes. Journal of Dairy Science, v.66, n.4, p.811-820, 1983.

STATISTICAL ANALYSIS SYSTEM - SAS. SAS users guide statistics. Version 5. Cary: 1991. 1028p.

SUÁREZ, B.J.; VAN REENEN, C.G.; GERRITS, W.J.J. et al. Effects of suplementing concentrates differing in carbohydrate composition in vela calf diets: II. Rumen development. Journal of Dairy Science, v.89, n.11, p.4376-4386, 2006.

TAMATE, H.; McGILLIARD, A.D.; JACOBSON, N.L. et al. Effect of various dietaries on the anatomical development of the 
stomach in the calf. Journal of Dairy Science, v.45, p.408-420, 1962.

VELOSO, C.M.; GONSALVES NETO, J.; GOMES, R.B. et al. Concentrado peletizado e farelado para bezerros leiteiros na fase de aleitamento: Desempenho. In: REUNIÃO ANUAL DA SOCIEDADE BRASILEIRA DE ZOOTECNIA, 43., 2006, João Pessoa. Anais... João Pessoa: Sociedade Brasileira de Zootecnia, 2006. (CD-ROM).

WARNER, R.G.; PROTER, J.C.; SLACK, T.S. Calf starter formulation for neonatal calves fed no hay. In: CORNELL NUTRITION CONFERENCE, 1973, Ithaca. Proceedings... Ithaca: Cornell University, 1973. p.116-122.

WARNER, R.G. Nutritional factors affecting the development of a functional ruminant - a historical perspective. In: CORNELL
NUtRition CONFEREnCE, 1991, Ithaca. Proceedings... Ithaca: Cornell University, 1991. p.1-12.

WILLIAMS, C.C.; THOMPSON JR., D.L.; BATEMAN II, H.G. et al. Effects of dietary protein and weaning age on hormone and metabolite concentrations in neonatal dairy calves. Journal of Dairy Science, v.84, p.226, 2001 (suppl. 1).

YU, P.; HUBER, J.T.; SANTOS, F.A.P. et al. Effects of ground, steamflaked, and steamrolled corn grains on performance of lactating cows. Journal of Dairy Science, v.81, n.3, p.777-783, 1998.

ZIEGLER, B.; LARSON, R.; CHESTER-JONES, H. et al. Pre- and post weaning performance of dairy heifer calves fed texturized or pelleted calf starters with or without intake enhancing flavors. Journal of Animal Science, v.84, p.365, 2006 (suppl. 1). 